\title{
Effects of photoperiod and temperature on the development of Bonagota cranaodes
}

\author{
M I R Y N D.A. C O R A C I I ${ }^{1}$, PA U L O H. G. Z A R B I N ${ }^{1}$, \\ MARIE B ENGTS O N ${ }^{2}$, A D A LÉCIO KOVALESKI ${ }^{3}$, \\ E VALDO F. V I L E L A ${ }^{4}$, L U C I A A L. TOREZ A N ${ }^{3}$, \\ E D U A R D R. H I C K L ${ }^{5}$ and P E T E R W I T Z A L L ${ }^{2}$ \\ ${ }^{1}$ Department Chemistry, Federal University of Parana, Curitiba-PR, Brazil, ${ }^{2}$ Chemical Ecology Group, Swedish University \\ of Agricultural Sciences, Alnarp, Sweden, ${ }^{3}$ EMBRAPA/CNPUV, Vacaria-RS, Brazil, ${ }^{4}$ Department Animal Biology, Federal \\ University of Viçosa, Viçosa-MG, Brazil and ${ }^{5}$ EPAGRI/Videira, Videira-SC, Brazil.
}

\begin{abstract}
The Brazilian apple leafroller, Bonagota cranaodes (Meyrick) (Lepidoptera: Tortricidae) is reared in the laboratory under a long-day (LD $14: 10 \mathrm{~h}$ ) and a short-day (LD $7: 17 \mathrm{~h}$ ) photoperiod at $22^{\circ} \mathrm{C}$, and under two different temperatures $\left(10-13{ }^{\circ} \mathrm{C}\right.$ and $21-22$ ${ }^{\circ} \mathrm{C}$ ). The development time from larval to adult eclosion do not differ between the two photoperiods, but did between the two temperature regimes. However, the larvae do not enter diapause, even under short day conditions and low temperatures. The number of adults obtained does not differ with temperature and light conditions. Field captures with pheromone traps show that Brazilian apple leafroller occurs in apple orchards throughout the year and the population densities are lower in winter. Accordingly, control measures should be taken during the off-season.
\end{abstract}

Key words. Diapause, field trapping test, insect control, monitoring, sex pheromone.

\section{Introduction}

Insects in temperate climate zones are challenged to endure harsh temperature regimes and the absence of food resources during winter. They survive such unfavourable conditions in diapause. Some univoltine species undergo an obligatory, genetically fixed diapause. In other univoltine and all multivoltine species, diapause is induced by external cues that indicate the end of the summer, such as decreasing day length or temperature (Beck, 1980; Tauber et al., 1986).

The Brazilian apple leafroller, Bonagota cranaodes (Meyrick) (Lepidoptera: Tortricidae), is considered to be a major leafroller pest of apple in Southern Brazil (Lorenzato, 1984; Kovaleski, 1992). Larvae feed mainly on leaves but will also attack fruits superficially when they are in contact with leaves. There is little information available about the biology of $B$. cranaodes but studies show that this insect occurs in apple orchards all year round at highly variable

Correspondence: M. D. A. Coracini, Department Chemistry, Federal Universityof Parana, Box 19081, 81530-990 Curitiba-PR, Brazil. Tel.: +55 41 33613174; fax: +55 41 33613186; e-mail: miryancoracini@quimica.ufpr.br population densities, necessitating multiple sprays (Lorenzato, 1984; Kovaleski, 1992; Eiras et al., 1994) .

Information on the seasonal cycle of a pest at different environmental conditions is vital to the understanding of its population dynamics. Therefore, present study examines (i) the role of photoperiod and temperature in the development of larvae and (ii) the occurrence of adult $B$. cranaodes in apple orchard throughout the year to discover whether $B$. cranaodes undergoes diapause in laboratory or field conditions.

\section{Materials and methods}

Insect rearing

Bonagota cranaodes were obtained from a laboratory at Embrapa, Vacaria, Brazil, where the insects are reared on a semiartificial agar-based diet (Mani et al., 1978), at $21{ }^{\circ} \mathrm{C}$, and a photoperiod of LD 14:10 h. Field-collected insects are added to the colony every year. Insects were reared from first-instar larvae until adults under four conditions, involving two photoperiods (LD $7: 17 \mathrm{~h}$ and LD $14: 10 \mathrm{~h}$ ) and two temperatures $\left(10-13{ }^{\circ} \mathrm{C}\right.$ and $\left.21-22^{\circ} \mathrm{C}\right)$.

(C) 2007 The Authors Journal compilation (C) 2007 The Royal Entomological Society 


\section{Development under different photoperiods}

Two containers ( $1.5 \mathrm{~L}$ of diet) infested with 500 first-instar larvae (first generation) were kept under a LD $7: 17 \mathrm{~h}$ photoperiods. The adults eclosing from these containers were counted daily and transferred for mating and oviposition to cages that were kept in the same room. Four days after the last moth had emerged, the diet container was checked for remaining larvae and pupae. These were transferred to plastic Petri dishes $(9 \times 3.5 \mathrm{~mm})$ containing moistened filter paper. Eclosed adults were counted daily.

The larvae hatching from the oviposition cages (second generation) were placed in batches of 500 into containers with $1.5 \mathrm{~L}$ of agar diet. One of these containers was kept under a LD $7: 17 \mathrm{~h}$ photoperiod and the other one under a LD $14: 10 \mathrm{~h}$ photoperiod, both at a constant temperature of $22{ }^{\circ} \mathrm{C}$. Adults were counted after eclosion and the diet was checked for dead larvae.

\section{Development under different temperatures}

In this experiment, 500 newly-hatched larvae (first generation) were placed in groups of 25 larvae into small plastic containers with $75 \mathrm{~g}$ of agar diet. The containers were kept inside two climatic chambers, one at a temperature of $10-13{ }^{\circ} \mathrm{C}$ and the other at a temperature of $21-22{ }^{\circ} \mathrm{C}$, both under a constant photoperiod (LD $7: 17 \mathrm{~h}$ ). The same procedure was used for counting dead larvae/pupae and adults eclosion as described above. Adults were transferred for mating and oviposition to cages that were kept in a climatic chamber.

The larvae hatching from the oviposition cages (second generation) were placed in groups of 25 larvae each into small plastic containers (with $75 \mathrm{~g}$ of agar diet), and kept inside the same climatic chamber as the first generation. Dead larvae/pupae and adults that had eclosed were counted.

\section{Field trapping tests}

Trap tests were carried out at Rubi Apple Orchard, VacariaRS, Brazil, from January to December, 2004. Tetra traps (Arn et al., 1979) were baited with $10 \mu \mathrm{g}$ of the optimized fourcomponent sex pheromone blend (Coracini et al., 2001), formulated on red rubber septa (Merck ABS, Dietikon, Switzerland). The chemical and isomeric purity of the com- pounds was $>99.5 \%$. Traps $(n=10)$ were placed at a distance of approximately $1.7 \mathrm{~m}$ from the apple trees. Traps were placed $5 \mathrm{~m}$ apart, and were arranged in random order in a line along tree rows. Traps were inspected once a week.

\section{Statistical analysis}

Prior to statistical analysis, data were checked for analysis of variance assumptions and, if needed, transformed to avoid heterogeneity of variances. The number of days required for $B$. cranaodes adults to emerge, and the number of adults obtained under different photoperiods, different temperatures and different generations, were compared using Fisher's exact test. $P<0.05$ was consisdered statistically significant.

\section{Results and discussion}

The development time from first-instar larvae to eclosion of adult was very similar under the long- and short-day photoperiods (Table 1). The mean development time in these experiments was in the range 52-59 days, which compares with a development time of 53.4 days for continuous laboratory-rearing under a LD 14:10 h photoperiod ( $n=12$ generations). There was no difference between the numbers of adults emerging under the two photoperiods (Table 1). Although the ecology of insect diapause has been studied extensively in insects, most of the available data concern insects from temperate zones, where insects are subject to marked seasonal changes in photoperiod, temperature and availability of food resources. Diapause is usually induced by decreasing day length (Chippendale and Reddy, 1973; Goettel and Philogène, 1978; Boyne et al., 1985). The situation is quite different in the Tropics because there are only minor seasonal changes in daylength (Tanzubil et al., 2000). Under such conditions, the key environmental factors influencing diapause are rainfall, temperature and food in conjunction with photoperiod (Adkisson et al., 1963; Scheltes, 1978; Denlinger, 1986; Kfir, 1993). Our results shows that exposure to a short daylength does not induce $B$. cranaodes to enter diapause, and has no influence on the reproductive behaviour during the two generations of exposure to different photoperiods. Observations of mating and oviposition behaviour under long and short photoperiod do not indicate a difference between the treatments. Matings occur within the first hour after lights off, and female oviposition behaviour is the same, under both photoperiods.

Table1. Development of Brazilian apple leafroller Bonagota cranaodes larvae under two different photoperiods.

\begin{tabular}{|c|c|c|c|c|c|c|}
\hline Treatment & Generation & Photocycle (LD) & Larvae used $(n)^{\mathrm{a}}$ & Dead insects $(n)$ & Adults emerged $(n)$ & Development time (days) ${ }^{\mathrm{b}}$ \\
\hline Dark & First & $7: 17 \mathrm{~h}$ & 500 & 33 & $326^{\mathrm{a}}$ & $51.9^{\mathrm{a}}$ \\
\hline Dark & First & $7: 17 \mathrm{~h}$ & 500 & 52 & $325^{\mathrm{a}}$ & $52.3^{\mathrm{a}}$ \\
\hline Dark & Second & $7: 17 \mathrm{~h}$ & 500 & 51 & $249^{\mathrm{a}}$ & $58.9^{\mathrm{a}}$ \\
\hline Light & Second & $10: 14 \mathrm{~h}$ & 500 & 43 & $228^{a}$ & $51.8^{\mathrm{a}}$ \\
\hline
\end{tabular}

aAll treatments began with recently-emerged larvae.

${ }^{b}$ Mean value for growth period from larvae to adult.

Within the same column and same generation, numbers followed by the same superscript letter are not significantly different (Fisher's exact test, $P>0.05$ ). 
Table 2. Development of Brazilian apple leafroller Bonagota cranaodes larvae under two different temperatures.

\begin{tabular}{lllllll}
\hline Temperature $\left({ }^{\circ} \mathrm{C}\right)$ & Generation & Photocycle $(\mathrm{LD})$ & Larvae used $(n)^{\mathrm{a}}$ & ${\text { Dead insects }(n)^{\mathrm{a}}}^{\mathrm{a}}$ & ${\text { Adults emerged }(n)^{\mathrm{a}}}^{\text {Development time }(\text { days })^{\mathrm{b}}}$ \\
\hline $10-13$ & First & $7: 17 \mathrm{~h}$ & 500 & 45 & $237^{\mathrm{a}}$ & $167.1^{\mathrm{a}}$ \\
$10-13$ & Second & $7: 17 \mathrm{~h}$ & 500 & 47 & $241^{\mathrm{a}}$ & $155.6^{\mathrm{a}}$ \\
$21-22$ & First & $7: 17 \mathrm{~h}$ & 500 & 34 & $273^{\mathrm{a}}$ & $45.3^{\mathrm{a}}$ \\
$21-22$ & Second & $7: 17 \mathrm{~h}$ & 500 & 41 & $257^{\mathrm{a}}$ & $42.8^{\mathrm{a}}$ \\
\hline
\end{tabular}

${ }^{a}$ All treatments began with recently-emerged larvae.

${ }^{\mathrm{b}}$ Mean value for growth period from larvae to adult.

Within the same column and same temperature, numbers followed by the same superscript letter are not significantly different from each other (Fisher test, $P>0.05$ ).

Larval development time from hatching until adult emergence depended on temperature, but a similar number of adults emerged for both temperatures (Table 2). There was no difference between the number of adults emerged for both generations and both temperatures $(P<0.02)$ (Table 2$)$. However, approximately 43 days was needed to obtain the first adult at $21-22{ }^{\circ} \mathrm{C}$, and 160 days at $10-13{ }^{\circ} \mathrm{C}(P<0.02)$. The results show that low temperature does not induce B. cranaodes to enter diapause.

In many insect species from temperate climate zones, larval exposure to low temperatures is not necessary for diapause development. However, low temperatures that might have occurred during the larval development could have an impact on diapause development (Veerman and Vaz Nunes, 1980). Many of the photoperiodic responses are also temperature-dependent, with temperature affecting circadian entrainment, photoperiodic summation and aspects of general physiology involved in diapause induction (Veerman and Vaz Nunes, 1980). For example, this is observed for the tortricidae species Adoxophyes orana, Choristoneura fumiferana and Endopiza viteana (Han and Bauce, 1996; Tobin et al., 2002; Milonas and Savopoulou-Soultani, 2004) and for the noctuidae specie Sesamia nonagrinoides (Fantinou et al., 2003). For B. cranaodes, the interaction between short
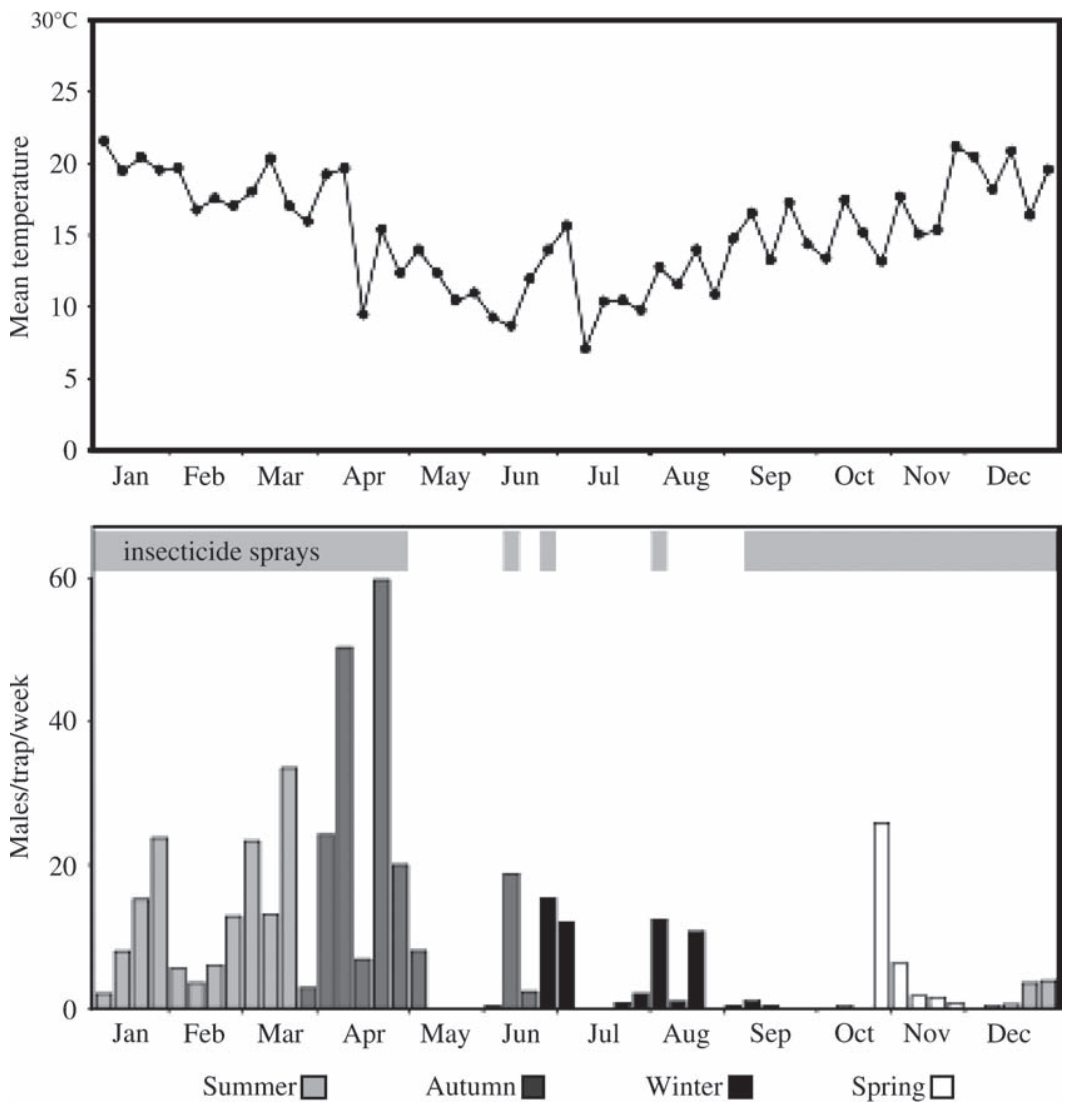

Fig. 1. Weekly mean air temperature and trap catch of Brazilian apple leafroller Bonagota cranaodes males in pheromone traps at Schio Orchard, Vacaria-RS, Brazil, from January to December 2004. 
day and low temperature does not lead to diapause (Table 2). Under these conditions, $B$. cranaodes larvae slow down theie growth and development. It may be that the low temperature provides a shorter period suitable for feeding, which in turn reduces metabolic functions and retards larval development.

In the present study, 4 days after the last moth had emerged, there are only few larvae at the last instars and few pupae remaining in the diet recipients for both generations in different photoperiods/temperatures, showing that the individuals do not stop the development at some stage.

The most important mortality factor is migration of larvae out of the diet boxes. During the last instars, B. cranaodes larvae try to find a safe place to pupate, and it is at this stage that they are more active and try to escape. Pieces of corrugated paper inside the diet recipients provide the larvae with places to pupate but, nevertheless, many of do not remain in the diet recipients.

Captures in pheromone traps show that $B$. cranaodes adults are present in the apple orchard all year around, even during the winter (Fig. 1). Rather high captures of B. cranaodes are recorded during the end of the peak growing season from February to April, when multiple insecticide sprays are applied to control B. cranaodes and Grapholita molesta infestations. This field test shows also that $10-\mu \mathrm{g}$ lures baited with the optimized four-component pheromone remain attractive over 6 months.

The control level recommended for B. cranaodes is when weekly pheromone trap captures surpass 30 males per trap. However, in autumn and winter, the grower sprays insecticide when any increase of the adult population is detected (June, July, and August) (Fig. 1). From September onward, there is frequent insecticide use due to the occurrence of B. cranaodes, G. molesta, and Anastrepha fraterculus (Diptera: Tephritidae).

Our field tests corroborate the results of the laboratory tests and confirm that $B$. cranaodes does not diapause. The adults are present all year around, despite the lower temperature and shorter day regime during winter. Population densities are lowest during the off-season and attempts should be made to further reduce population densities before the onset of the new apple growing period.

\section{Acknowledgements}

We thank Jorge A. B. Pereira for assistance during the field bioassays, and Agropecuária Schio Ltda - Agronomist Jaques Dias (Vacaria), for use of the apple orchard and assistance in the field. This study was supported by the Conselho Nacional de Desenvolvimento Cient'fico e Tecnológico (CNPq), International Foundation for Science (IFS)/MISTRA, and Empresa Brazileira de Pesquisa Agropecuária (EMBRAPA/ CNPUV).

\section{References}

Adkisson, P.L., Bell, R.A. \& Wellso, S.G. (1963) Environmental factors controlling the induction of diapause in the pink boll- worm, Pectinophora gossypiella. Journal of Insect Physiology, $\mathbf{9}$, 299-230.

Arn, H., Rauscher, S. \& Schmid, A. (1979) Sex attractant formulations and traps for the grape moth Eupoecilia ambiguella $\mathrm{Hb}$. Mitteilungen der Schweizerischen Entomologischen Gesellschaft, 52, 49-55.

Beck, S.D. (1980) Insect Photoperiodism, 2nd edn. Academic Press, New York, New York.

Boyne, J.V., Rock, G.C. \& Nelson, L.A. (1985) Diapause in Platynota idaeusalis (Lepidoptera: Tortricidae): effects of temperature, photoperiod, and time of inoculation in the field on diapause termination. Environmental Entomology, 14, 790-796.

Chippendale, G.M. \& Reddy, A.S. (1973) Temperature and photoperiod regulation of diapause of the southwestern corn borer Diatraea grandiosella. Journal of Insect Physiology, 19, 1397-1408.

Coracini, M.D.A., Bengtsson, M., Reckziegel, A. et al. (2001) Identification of a four-component sex pheromone blend in Bonagota cranaodes (Lepidoptera: Tortricidae). Journal of Economic Entomology, 94, 911-914.

Denlinger, D.L. (1986) Dormancy in tropical insects. Annual Review of Entomology, 31, 239-264.

Eiras, A.E., Delmore, L.R.K., Parra, J.R.P., Pique, M.P.R., Vilela, E.F. \& Kovaleski, A. (1994) Biologia comparada da lagarta enroladeira Phtheocroa cranaodes Meyrick (Lepidoptera: Tortricidae) em duas dietas artificiais. Anais da Sociedade Entomológica do Brasil, 23, 251-257.

Fantinou, A.A., Kourti, A.T. \& Saitanis, C.J. (2003) Photoperiodic and temperature effects on the intensity of larval diapause in Sesamia nonagrinoides. Physiological Entomology, 28, 82-87.

Goettel, M.S. \& Philogène, B.J.R. (1978) Effects of photoperiod and temperature on the development of a univoltine population of the banded woollybear, Pyrrharctia (Isia) isabella. Journal of Insect Physiology, 24, 523-527.

Han, E.-N. \& Bauce, E. (1996) Diapause development of spruce budworm larvae, Choristoneura fumerana (Clem.) (Lepidoptera: Tortricidae), at temperatures favouring post-diapause development. Canadian Entomologist, 128, 167-169.

Kfir, R. (1993) Diapause termination in Chilo partellus in the laboratory. Annals of Applied Biology, 123, 1-7.

Kovaleski, A. (1992) MIP Fruteiras de clima temperado. Manejo integrado de pragas e nematóides (ed. by O.A. Fernandes, A.C.B. Correia \& S. Bortoli), pp. 271-287. UNESP, Jaboticabal.

Lorenzato, D. (1984) Ensaio laboratorial de controle da 'traça da maçã' Phtheochroa cranaodes Meyrick, 1937 com Bacillus thuringiensis Berliner e inseticidas químicos. Agronomia Sulriograndense, 20, 157-163.

Mani, E., Riggenbach, W. \& Mendik, M. (1978) Zucht des Apfelwicklers (Laspeyresia pomonella) (L.) auf künstlichem Nährboden, 1968-78. Mitteilungen der Schweizerischen Entomologischen Gesellschaft, 51, 315-326.

Milonas, G.P. \& Savopoulou-Soultani, M. (2004) Diapause termination in overwintering larvae of a Greek strain of Adoxophyes orana (Lepidoptera: Tortricidae). Environmental Entomology, 33, 513-519.

Scheltes, P. (1978) The condition of the host plant during aestivation-diapause of the stalk borers Chilo partellus and Chilo orichalcociliella in Kenya. Entomologia Experimentalis et Applicata, 24, 479-488.

Tanzubil, P.B., McCaffery, A.R. \& Mensah, G.W.K. (2000) Diapause termination in the millet stem borer, Coniesa ignefusalis (Lepidoptera: Pyralidae) in Ghana as affected by photoperiod and moisture. Bulletim of Entomological Research, 90, 89-95. 
Tauber, M.J., Tauber, C.A. \& Masaki, S. (1986) Seasonal Adaptations of Insects. Oxford University Press, New York, New York.

Tobin, P.C., Nagarkatti, S. \& Saunders, M.C. (2002) Diapause maintenance and termination in grape berry moth (Lepidoptera: Tortricidae). Environmental Entomology, 31, 708-713.
Veerman, A. \& Vaz Nunes, M. (1980) Circadian rhythmicity participates in the photoperiodic determination of diapause in spider mites. Nature, 287, 140-141.

Accepted 12 December 2006

First published online 26 July 2007 